\title{
Comparative studies about fungal colonization and deoxynivalenol translocation in barley plants inoculated at the base with Fusarium graminearum, Fusarium culmorum and Fusarium pseudograminearum
}

\author{
Francesco Pecoraro ${ }^{1}$, Marta Giannini ${ }^{1}$, Giovanni Beccari ${ }^{2}$, Lorenzo Covarelli ${ }^{2}$, Gianfranco Filippini ${ }^{1}$, Annamaria Pisi $^{1}$, \\ Paola Nipoti ${ }^{1}$ and Antonio Prodi ${ }^{1}$ \\ ${ }^{1}$ Department of Agricultural and Food Science, University of Bologna, Viale G. Fanin 44, 40127, \\ Bologna, Italy \\ ${ }^{2}$ Department of Agricultural, Food and Environmental Sciences, University of Perugia, Borgo XX Giugno 74, 06121, \\ Perugia, Italy \\ e-mail: antonio.prodi@unibo.it
}

\begin{abstract}
Fusarium crown rot (FCR), an important disease of wheat and barley, is mainly caused by Fusarium graminearum, F. culmorum and F. pseudograminearum, which are also responsible for mycotoxin production. This is the first comparative investigation of their colonization on barley plants after stem base inoculation. At plant maturity, FCR symptoms were visually evaluated, fungal biomass was quantified by Real-Time quantitative PCR and deoxynivalenol (DON) was detected by enzyme-linked immunosorbent assay (ELISA). All the inoculated strains caused the typical FCR necrotic symptoms. Real-Time PCR analysis showed that $F$. graminearum and $F$. culmorum were present in the head tissues, while $F$. pseudograminearum colonized only up to the area including the second node of the stem. Conversely, DON was detected up to the head for all the three species. This study shows that, as already demonstrated in previous research for wheat, DON may be detected up to the head as a consequence of stem base infection by the three FCR agents.
\end{abstract}

Key words: Hordeum vulgare, barley, Fusarium crown rot, Real-Time quantitative PCR, trichothecenes, ELISA

\section{Introduction}

Fusarium head blight (FHB) and Fusarium crown rot (FCR) are two of the most important cereal diseases, including soft wheat (Trtiticum aestivum L.), durum wheat (Triticum durum Desf.), barley (Hordeum vulgare L.), oats (Avena sativa L.) and maize (Zea mays L.). FHB and FCR are caused by fungal microorganisms belonging to the genus Fusarium (Dyer et al. 2009, Xu and Nicholson 2009). FHB occurs during anthesis time, when environmental conditions are particularly humid (Engle et al. 2004). FHB symptoms include partial or total head desiccation, with the appearance of one or more prematurely bleached spikelets, easily observed on wheat especially when it has not yet reached the full ripening stage (Scherm et al. 2013). FCR occurs where dry climatic conditions prevail and where minimum tillage, stubble retention and similar conservation agricultural practices are used (Lamprecht et al. 2006, Smiley et al. 2005). In fact, infected stubble is the principal inoculum source for FCR (Southwell et al. 2003, Smiley et al. 2005). FCR symptoms vary according to the time of infection. When the fungus attacks at an early stage, just after sowing, pre- and post-emergence seedling death occurs, with brown discoloration on the coleoptiles, roots and stems. Conversely, if the infection starts later in the season, brown lesions appear on the first two or three internodes of the main stem and tiller abortion occurs. The presence of whiteheads with shriveled grain or no grain is easily observed when wheat plants are immature (Scherm et al. 2013). The main Fusarium species, responsible for FCR and FHB, are: Fusarium graminearum Schwabe, Fusarium culmorum (W.G. Smith) Sacc., Fusarium avenaceum (Corda) Sacc. and Fusarium pseudograminearum (O'Donnell \& T. Aoki) (Xu and Nicholson 2009, Hogg et al. 2010, Knight and Sutherland 2016). F. graminearum prefers warmer weather and is present mainly in central and southeastern Europe (Xu and Nicholson 2009). F. culmorum is traditionally reported to be mainly responsible of FHB in northern, central and western Europe (Parry et al. 1995, de Nijs et al. 1997, Muthomi et al. 2000). Recently, due to climate changes, the habitats of F. culmorum and $F$. graminearum are overlapping, increasing the incidence of FHB and FCR (Waalwijk et al. 2003, Jennings et al. 2004, Xu et al. 2005, West et al. 2012). F. pseudograminearum is more widespread in the Australian continent, North America and in many other cereal-growing regions around the world (Burgess et al. 2001, Smiley et al. 2005). It is predominantly associated with FCR, whereas F. graminearum mainly with FHB (Akinsanmi et al. 2004). 
These pathogens are responsible for quantitative damages, with significant yield losses (Hollaway et al. 2013, Nielsen et al. 2014) and, in particular when they cause FHB, of qualitative damages, due to mycotoxin accumulation in the grains. In fact, these three Fusarium species are all able to biosynthesize mycotoxins, in particular deoxynivalenol (DON), belonging to the group B of trichothecenes (Bottalico and Perrone 2002, Xu and Nicholson 2009). This secondary metabolite is highly dangerous for human and animal health (Antonissen et al. 2014). For this reason, the European Commission has established legal limits for DON in unprocessed cereals grains (1.25 $\left.\mathrm{mg} \mathrm{kg}^{-1}\right)$ and unprocessed durum wheat grains $\left(1.75 \mathrm{mg} \mathrm{kg}^{-1}\right)$ with the European directives EC $\mathrm{n} .1881 / 2006$ and $126 / 2007$. Several studies frequently detected DON in barley grains, malt and also beer (Schwarz 2017). In particular, the presence of DON in malting barley samples in Europe, including Italy, seems to be stable over the years and generally below legal limits (Berguete 2012, Beccari et al. 2016, Beccari et al. 2017). During beer production process, DON seems to be reduced with respect to the raw material, but its levels may increase during malting, in particular during the germination phase (Schwarz 2017).

The epidemiology of FHB, especially on wheat, is well known (Xu and Nicholson 2009, Scherm et al. 2013) and symptom gravity is often associated with a high proliferation of Fusarium biomass and a significant accumulation of mycotoxins (Pancaldi et al. 2010, Nielsen et al. 2014). Conversely, for FCR, the relationship between symptom severity, fungal biomass and mycotoxin accumulation is still poorly understood, because Fusarium causal agents do not directly colonize the head. Recently, several studies (Mudge et al. 2006, Covarelli et al. 2012, Winter et al. 2013, Moretti et al. 2014, Beccari et al. 2018) investigated the colonization process of different Fusarium species and their possible systemic movement along soft and durum wheat plants after stem base inoculation. In particular, Covarelli et al. (2012), Winter et al. (2013) and Moretti et al. (2014), investigating also DON translocation during FCR progress, revealed the presence of this secondary metabolite in wheat heads and in the grains, even when Fusarium was not detected in these parts of the plant. Most of FCR studies were focused on wheat, however, also barley through the years increased its importance, in parallel with the increase of the economic relevance of malt industry with the establishment of new microbreweries, especially in Italy (The Brewers of Europe 2015). Fungi belonging to the genus Fusarium represent unwanted microorganisms for the quality of final malt and beer as well as for beer consumers' health due to mycotoxin contamination related to their presence (Sarlin et al. 2005, Wolf-Hall 2007, Christian et al. 2011, Oliveira et al. 2013, Bertuzzi et al. 2011, Hückelhoven et al. 2018). Furthermore, one of the main concerns of the malt industry is the gushing phenomenon (Garbe et al. 2008), which, as reported by some authors, seems to be influenced by the presence of hydrophobins produced by FHB pathogens (Sarlin et al. 2005, Nielsen et al. 2014). Despite the issues, there is little in literature on the barley colonization process by Fusarium species compared to the extensive literature concerning wheat.

As already shown in wheat (Mudge et al. 2006, Covarelli et al. 2012, Winter et al. 2013, Moretti et al. 2014), FCR is a potential additional source of grain contamination with Fusarium mycotoxins. Thus, the objective of this study was to investigate the ability of F. graminearum, F. culmorum and $F$. pseudograminearum to systemically colonize barley plants starting from the stem base by visual, scanning electron microscope and Real-Time PCR methods and to verify the possible DON accumulation in the head.

To our knowledge, this is the first study investigating the potential systemic growth of Fusarium species and DON translocation from stem base to the head as a consequence of FCR development in barley.

\section{Materials and methods}

\section{Plant material}

Seeds of cv Tunika, a commercial barley cultivar, widely used in malt and livestock industry in Italy and susceptible to $\mathrm{FCR}$, were surface sterilized with sodium hypochlorite $(\mathrm{NaClO})$ with $2 \%$ available chlorine for 5 min and rinsed six times with sterile deionized water. After the pre-germination process, barley seedlings were individually transplanted into plastic pots filled with a mix of autoclaved sand, peat and vermiculite (ratio 1:1:1 v/v/v) and placed in a greenhouse at $24{ }^{\circ} \mathrm{C} \pm 2{ }^{\circ} \mathrm{C}$ day $/ 18^{\circ} \mathrm{C} \pm 2{ }^{\circ} \mathrm{C}$ night, $14 / 10 \mathrm{~h}$ light/dark cycle, with 30000 lux light intensity. At $\mathrm{BBCH} 10$ growth stage (the first leaf through coleoptile), a polyvinyl chloride (PVC) collar ( $3 \mathrm{~cm}$ long, $10 \mathrm{~mm}$ internal diameter) was applied around the emerging first leaf to ensure the contact of the fungal inoculum with the basal portion of barley seedlings (Simpson et al. 2000). The experiment was organized with randomized block experimental design, with three replicates per each treatment. 


\section{Fungal material and inoculation procedure}

The Fusarium species used for barley stem base inoculations were: F. culmorum (strain Fc820), F. graminearum (strain Fg913), both present in the collection of the Laboratory of Phytopathological Micology (DISTAL - University of Bologna, Italy) and F. pseudograminearum (strain CS3427, kindly supplied by Dr. D. Gardiner, Commonwealth Scientific and Industrial Research Organisation CSIRO, Brisbane, Australia). The strains used were selected for their ability to cause FCR and were all DON producers. The inoculation was performed at BBCH 12 growth stage (two leaves unfolded) as previously described by Covarelli et al. (2012). For each fungal species, the inoculum consisted of V8 gel (10g of Bacto Agar, $100 \mathrm{ml}$ of V8 juice agar and $400 \mathrm{ml}$ of deionized sterile water) mixed with a conidial suspension obtained as described in Purahong et al. (2012) with a final concentration of $1 \times 10^{6}$ macroconidia/ml. Two $\mathrm{ml}$ of the inoculum was injected into the space between barley seedlings and the PVC collars of each plant. V8 gel, amended with deionized sterile water, was used as a control for non-inoculated plants. A total of 184 plants (46 plants for four treatments with three replicates of 15 plants each, plus 1 plant for scanning electron microscopy observations) were assayed.

\section{FCR visual assessment}

At BBCH 89 growth stage (grain fully ripe), visual observations were carried out on all barley plants. In detail, plants were taken out from the soil and FCR presence was assessed using three parameters: a) total number of developed stems (main stem and tillers); b) number of necrotic stems (main stem and tillers); c) necrosis extension along the stem. This last parameter was assessed by dissecting each stem into four segments: segment I (inoculated area, adjacent to the crown, including the part just above the first node), segment II (the area including the second node), segment III (the area adjacent to the flag leaf) and segment IV (head). After visual observations, segments were allowed to dry at $45^{\circ} \mathrm{C}$ for $24 \mathrm{~h}$ and then finely ground with liquid nitrogen by mortar and pestle. Each ground sample, obtained from each replicate of 15 plants, was divided into two sub-samples, one for DNA extraction and Real-Time quantitative PCR and one for DON quantification.

\section{DNA extraction and quantification of fungal biomass by Real-Time quantitative PCR}

DNA extraction was carried out on barley ground material, from different plant segments, following the protocol described by Alkadri et al. (2013). The total DNA was quantified with a Nanodrop Spectrophotometer ND-1000 and each sample was diluted with Dnase free sterile water to obtain the same concentrations. Real-Time PCR assays were carried out in a AbiPrism 7000 Real-Time detection system (Applied Biosystems), using SYBR ${ }^{\circ}$ Green chemistry. Amplification mixtures were prepared with GoTaq ${ }^{\circ}$ qPCR Master Mix (Promega), in a final volume of 25 $\mu \mathrm{l}$ with primer concentrations of $0.3 \mathrm{nM}$, Rox Fluorophore and $5 \mu \mathrm{l}$ of DNA. Samples were analyzed in duplicate. DNA species-specific loci were amplified by primers: C51ENDF F (5'-AACTGAATTGATCGCAAGC-3') and C51ENDF R (5'-CCCTTCTTACGCCAATCTC-3') (Covarelli et al. 2012) for F. culmorum; Fg16N F (5'-ACAGATGACAAGATTCAGGCACA-3') and Fg16N R (5'-CTTTGACATCTGTTCAACCCA-3' (Nicholson et al. 1998) for F. graminearum; Fptri3e $F$ (5'-CAAGTTTGATCCAGGGTAATCC-3') and Fptri3e R (5'-GCTGTTTCTCTTAGTCTTCCTCA-3') (Khudhair et al. 2014) for F. pseudograminearum. Thermal profiles were optimized as follows: $10 \mathrm{~min}$ at $95^{\circ} \mathrm{C}$, followed by 40 cycles at $94^{\circ} \mathrm{C}$ for $30 \mathrm{~s}$, specific annealing temperature of each primer $\left(64^{\circ} \mathrm{C}\right.$ for $F$. graminearum and $60^{\circ} \mathrm{C}$ for $F$. pseudograminearum and F. culmorum) for $45 \mathrm{~s}$. Concentrations of standard DNA of F. graminearum, F. culmorum and F. pseudograminearum were quantified with a Nanodrop Spectrophotometer ND-1000. After quantification, a dilution series from 5000 pg to 5 pg of each Fusarium spp. DNA with a serial dilution factor of 10 was produced to setup standard curves. Amplification specificity check occurred in the thermal dissociation amplicon analysis, performed at the end of each reaction, bringing the products at $95^{\circ} \mathrm{C}$ for $15 \mathrm{~s}, 60^{\circ} \mathrm{C}$ for $20 \mathrm{~s}$ and $95^{\circ} \mathrm{C}$ for $30 \mathrm{~s}$, with readings every $0.3^{\circ} \mathrm{C}$. Amplification products were also checked on a $1 \%$ agarose gel, dyed with a $0.4 \mu \mathrm{g} \mathrm{m} \mathrm{l}^{-1}$ ethidium bromide solution and visualized under UV light. The limit of detection of fungal biomass was $5 \mathrm{pg}$.

\section{Deoxynivalenol quantification}

A total of $10 \mathrm{~g}$ of ground barley heads (segment IV) and $1 \mathrm{~g}$ of ground plant tissue from each of segments I, II and III were used to analyze DON presence using an AgraQuant ${ }^{\circledR}$ ELISA kit Deoxynivalenol Assay 0.25/5.0 (RomerLabs ${ }^{\circledR}$ ). DON extraction and determination were performed according to manufacturer's protocols. Optical densities of samples and of standard curves were estimated by a spectrophotometer (OpsysMR, Dynex technologies) using a $450 \mathrm{~nm}$ filter. The limit of detection (LOD) was $200 \mu \mathrm{g} \mathrm{kg}^{-1}$ and the limit of quantification (LOQ) was $250 \mu \mathrm{g} \mathrm{kg}{ }^{-1}$. 


\section{Mycological analysis}

Stem samples for each treatments were collected, surface-disinfected and plated on potato dextrose agar (PDA, Difco). They were incubated for 7 days at $25^{\circ} \mathrm{C}$ to isolate the mycoflora.

\section{Statistical analysis}

Data from visual assessments (proportion of plants with FHB symptoms) were analyzed by Generalized Linear Models with binomial error and logit link. A dispersion parameters was used to account for overdispersion (Faraway, 2006). Back transformed proportions were derived and pairwise comparisons were performed by using generalized linear hypothesis testing, with family-wise error rate, according to procedure suggested by Bretz et al. (2011). Data analyses were performed suggested the R stastical environment (R core Team 2017). Data from quantification of fungal biomass and DON accumulation were statistically analyzed by the software Statgraphics 2.1. The comparison of the averages of multiple sets of data, was performed by analysis of variance (ANOVA) with a significant level of $p \leq 0.05$ and the results were compared with the post-hoc Tukey HSD test.

\section{Scanning electron microscopy sample preparation}

A single plant, randomly taken from all the replicates of each treatment, was selected and a small portion (5-6 $\mathrm{mm}$ in length) of each segment (as previously described) was taken and processed for Scanning Electron Microscopy (SEM) observations, following the methodology described by Covarrubias et al. (2014). The specimens were then dried with a critical point drier unit Emitech K850 (Emitech Ltd, Ashford, England) mounted on aluminum stubs with double stick tape and coated with gold-palladium film using an ion sputtering unit Emitech K500 (Emitech Ltd). Samples were observed with a Philips 515 SEM (Philips) at $10 \mathrm{kV}$, and pictures were taken with a Nikon 5400 Coolpix digital camera (Nikon).

\section{Results \\ FCR visual assessment}

Visual observation data are reported in Table 1. No statistical differences in the degree of tillering (average values ranged from 10.38 to 11.89 of stems per plant) among the different treatments were recorded.

The typical FCR necrosis symptoms were present after inoculation with all the three Fusarium species, confirming their ability to cause FCR both in the main stem and in the secondary ones (tillers). In detail, Fc820 caused an average value of $39.85 \%$ of necrotic stems, significantly higher than that caused by CS3427 (22.73\%), which were not statistically different from Fg913 (25.93\%). The percentage of necrotic stems in the non-inoculated plants was significantly lower $(10.34 \%)$ compared with that of inoculated plants. Data about segments I, II and III were not significantly different among the three treatments but differed from that of the non-inoculated plants. No FCR symptoms were observed in segment IV (head tissues), data not shown.

Table 1. Average values of the parameters assessed by visual observation of barley plants following stem-base inoculation with F. culmorum (Fc820), F. graminearum (Fg913) and F. pseudograminearum (CS427) and in the non-inoculated plants. $p$ values indicate significant differences (Wald $F$ tests for quasibinomial fit) if $p \leq 0.05$, letters $(a, b, c)$ indicate the statistical differences between treatments following generalized linear hypothesis testing (Bretz et al. 2011).

\begin{tabular}{cccccc}
\hline $\begin{array}{c}\text { Inoculation } \\
\text { treatment }\end{array}$ & $\begin{array}{c}\text { Number of } \\
\text { total stems } \\
\text { per plant }\end{array}$ & $\begin{array}{c}\text { Necrotic } \\
\text { stems (\%) }\end{array}$ & $\begin{array}{c}\text { Stems with } \\
\text { necrosis } \\
\text { (segment I) } \\
(\%)\end{array}$ & $\begin{array}{c}\text { Stems with } \\
\text { necrosis } \\
\text { (segment II) } \\
(\%)\end{array}$ & $\begin{array}{c}\text { Stems with } \\
\text { necrosis } \\
\text { (segment III) } \\
(\%)\end{array}$ \\
\hline Fc820 & 10.56 & $39.85 \mathrm{a}$ & $33.33 \mathrm{a}$ & $5.33 \mathrm{a}$ & $1.33 \mathrm{a}$ \\
Fg913 & 10.99 & $25.93 \mathrm{ab}$ & $20.66 \mathrm{a}$ & $4.33 \mathrm{a}$ & $0.67 \mathrm{ab}$ \\
CS3427 & 11.89 & $22.73 \mathrm{~b}$ & $20.00 \mathrm{a}$ & $2.17 \mathrm{a}$ & $0.83 \mathrm{ab}$ \\
Non-inoculated & 10.38 & $10.34 \mathrm{c}$ & $10.34 \mathrm{~b}$ & $0.00 \mathrm{~b}$ & $0.00 \mathrm{~b}$ \\
$p$ value & n.s. ${ }^{1}$ & $6 * 10^{-7}$ & $4.8^{*} 10^{-5}$ & $2.7^{*} 10^{-6}$ & 0.02 \\
\hline
\end{tabular}

${ }^{1}$ n.s. $=$ non statistically significant 


\section{Quantification of fungal biomass by Real-Time quantitative PCR}

Table 2 shows the amounts of fungal DNA per plant dry weight (ng g ${ }^{-1}$ d.w.), of strains Fc820, Fg913 and CS3427 in the different plant segments, as quantified by Real-Time PCR. Non-inoculated plants were also analyzed to verify the possible presence of the tested Fusarium species. All the amplifications were specific. The melting temperature for F. culmorum DNA was $79.3^{\circ} \mathrm{C}$, for F. graminearum DNA was $80.4{ }^{\circ} \mathrm{C}$ and for $F$. pseudograminearum DNA was $75.8^{\circ} \mathrm{C}$, in line with the instrument parameters (data not shown). The presence of Fc 820 biomass in segments I and II (1464.05 $\mathrm{ng} \mathrm{g}^{-1} \mathrm{~d}$.w. and $1148.28 \mathrm{ng} \mathrm{g}^{-1}$ d.w., respectively) was significantly higher than the biomass detected in segments III and IV (17.31 ng g-1 d.w. and $1.15 \mathrm{ng} \mathrm{g}^{-1} \mathrm{~d}$.w., respectively). The highest level of Fg913 biomass was detected in segment I with $145.68 \mathrm{ng} \mathrm{g}^{-1} \mathrm{~d}$.w., significantly different from the levels found in segments III (1.23 ng g-1 d.w.) and IV (0.59 $\mathrm{ng} \mathrm{g}^{-1} \mathrm{~d}$.w.). The levels of CS3427 biomass in the different barley segments were not statistically significant. F. culmorum, F. graminearum and F. pseudograminearum biomass was not detected in any non-inoculated plant.

Table 2. Amount of fungal biomass, expressed as ng of fungal DNA $\mathrm{g}^{-1}$ plant dry weight, in the different barley segments following stem-base inoculation with F. culmorum (Fc820), F. graminearum (Fg913) and F. pseudograminearum (CS3427). $p$ values indicate ANOVA test significance if $p \leq 0.05$, letters $(a, b, c)$ indicate significant differences between treatments following the post hoc Tukey HSD test.

\begin{tabular}{ccccc}
\hline Segments & Fc820 & Fg913 & CS3427 & Non-inoculated \\
\hline I & $1464.05 \mathrm{a}$ & $145.68 \mathrm{a}$ & 492.9 & n.d. $^{* *}$ \\
II & $1148.28 \mathrm{a}$ & $58.51 \mathrm{ab}$ & 68.56 & n.d. \\
III & $17.31 \mathrm{~b}$ & $1.23 \mathrm{~b}$ & n.d. & n.d. \\
IV & $1.15 \mathrm{~b}$ & $0.59 \mathrm{~b}$ & n.d. & n.d. \\
$p$ value & $\leq 0.05$ & $\leq 0.05$ & n.s. &
\end{tabular}

\section{Deoxynivalenol quantification}

Table 3 shows the average levels of DON $\left(\mathrm{mg} \mathrm{kg}^{-1}\right)$ in the different segments of inoculated and non-inoculated barley plants. The highest DON levels were detected with strain Fc820. In details, the highest levels were detected in segments I and II (12.12 and $8.26 \mathrm{mg} \mathrm{kg}^{-1}$, respectively) of plants inoculated with strain Fc820, which were statistically different from DON levels detected in segments III and IV ( 0.71 and $0.28 \mathrm{mg} \mathrm{kg}^{-1}$ respectively). With regard to strains Fg913 and CS3427, DON accumulation was not significantly different between segments. DON was not detected in any non-inoculated plant.

Table 3. Amount of deoxynivalenol $\left(\mathrm{mg} \mathrm{kg}^{-1}\right)$, in the samples from different barley segments following stem-base inoculation with F. culmorum (Fc820), F. graminearum (Fg913) and F. pseudograminearum (CS3427) and non-inoculated plants. $p$ values indicate ANOVA test significance if $p \leq 0.05$, letters $(a, b, c)$ indicate significant differences between treatments following the post hoc Tukey HSD test.

\begin{tabular}{ccccc}
\hline Segments & Fc820 & Fg913 & CS3427 & Non-inoculated \\
\hline I & $12.12 \mathrm{a}$ & 3.53 & 2.87 & n.d. ${ }^{* *}$ \\
II & $8.26 \mathrm{a}$ & 0.44 & 3.37 & n.d. \\
III & $0.71 \mathrm{~b}$ & 0.26 & 0.27 & n.d. \\
IV & $0.28 \mathrm{~b}$ & 0.23 & 0.48 & n.d. \\
$p$ value & $\leq 0.05$ & n.s. $^{*}$ & n.s. & \\
\hline
\end{tabular}

${ }^{*}$ n.s. = non statistically significant; ${ }^{* *}$ n.d. $=$ not detected

\section{Scanning Electron Miscroscopy observations}

Samples from plants inoculated with F. culmorum (Fc820) and F. graminearum (Fg913) were subject to SEM observations. They showed hyphal colonization in the area adjacent to the crown, including the first node (segment I) and in the area including the second node (segment II) (Figs. 1a-f). Conversely, samples from plants inoculated with F. pseudograminearum (CS3427) showed hyphal colonization only in segment I (Fig. 1g). No hyphae were detected in the area adjacent to the flag leaf (segment III) and in the head (segment IV) for all the treatments. No hyphal presence was detected in non-inoculated plants. 

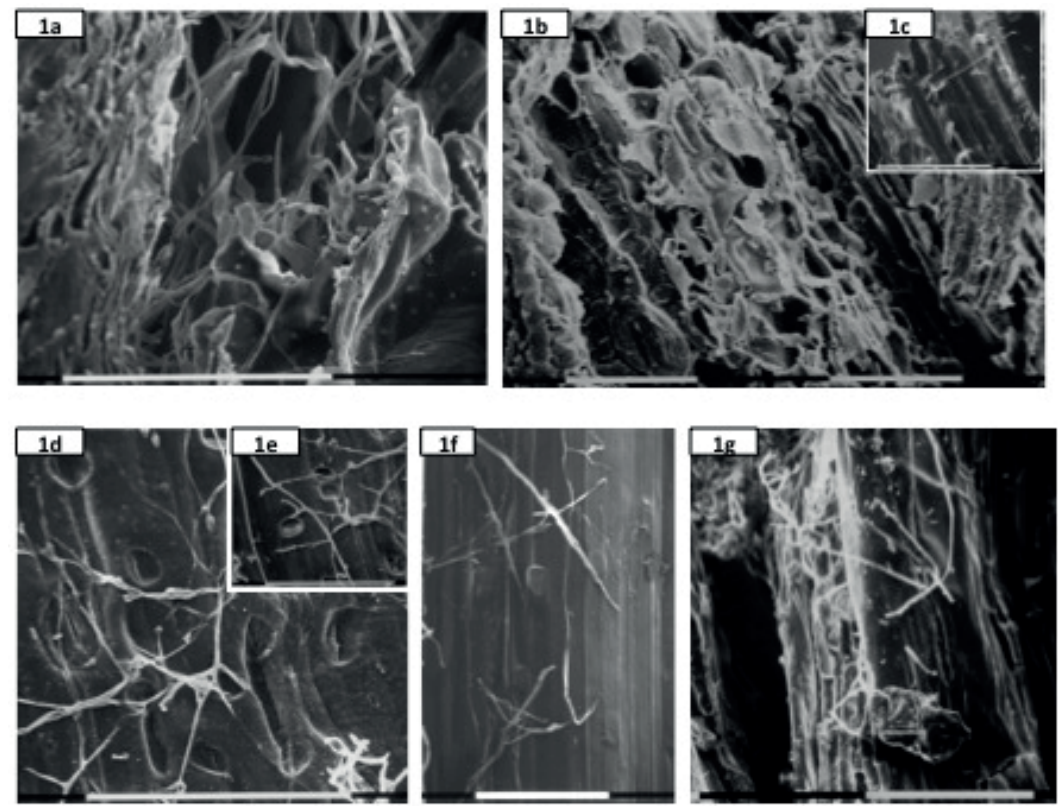

Fig. 1. Scanning electron microscopy micrographs. Detection of fungal colonization in different segments of the stem of barley plants following inoculation with F. culmorum (Fc820), $F$. graminerum (Fg913) and F. pseudograminearum (CS3427). 1a-1c. Hyphae of $F$. culmorum ( $F c 820)$ on the surface of the stem in the area adjacent to the crown, including the first node (segment I) (1a) and in the area including the second node (segment II) (1b). Detail of hyphae inside the stem in segment II (1c). The epidermal layer, even if with a low hyphal concentration, appears damaged. 1d-1f. Hyphae of F. graminearum (Fg913) in segments I (1d) and II (1f) of the barley stem. In this case, the epidermal layer, even if the hyphal concentration is high, appears well preserved. In the insert (1e) hyphae penetrating a stomata at the level of segment I. $1 \mathrm{~g}$. Hyphae of $F$. pseudograminearum (CS3427) on segment I (1g) of barley stem. (bars $=0.1 \mathrm{~mm}$ )

\section{Discussion}

In this study, the behaviour of the three main causal agents of FCR of barley, F. culmorum, F. graminearum and F. pseudograminearum, was analysed during the colonization of barley after stem base inoculation. In addition, DON translocation along the barley plant was studied as a possible additional source of grain contamination. The three FCR pathogens are all well-known producers of DON, a mycotoxin subject to EU legal limits in harvested grains, due to its toxicity and toxicity to animals and humans.

It has been observed that stem necrosis was present in all the barley plants inoculated with the three FCR causal agents and that these pathogens were also able to spread into the tillers during plant development when inoculated at the base of the main stem. Comparing the percentages of necrotic stems, the F. culmorum strain used in this experiment showed the highest aggressiveness, even if all three Fusarium species were able to cause FCR necrosis up to the area adjacent to the flag leaf node (segment III). The necrotic symptoms detected in the stems of non inoculated plants was probably due to a blockage-effect of the PVC collar; this was confirmed by fungal biomass quantification with Real-Time PCR that showed the absence of Fusarium biomass in non-inoculated plants and necrotic tissue isolation on agar medium showed no presence of Fusaria or Microdochium strains (data not shown).

Stephens et al. (2008), studying the early events of FCR disease caused by F. graminearum in soft wheat, described the penetration mechanism of this pathogen in three stages: the first as lateral penetration, the second as a descent of the fungus through the roots and the third as penetration through the lumen of the main culm and parenchyma. Knight and Sutherland (2016) reported for the first time the penetration mechanisms for F. pseudograminearum: an initial epidermal penetration, mostly through stomata apertures, progressing into the parenchymatous hypoderm, and leading to the typical discoloration used as visual assessment of the disease. Furthermore these authors described the ability of the fungus to colonize at least three internodes, with frequent xylem vessels and phloem cell occlusion. 
In the present study, Real-Time PCR analysis confirmed also the ability of the three Fusarium species analyzed to colonize barley plants at different heights. F. culmorum (strain Fc820) and F. graminearum (strain F913) were present up to the segment IV, corresponding to the head portion, but in high concentrations only up to the segment II. This finding was also confirmed by SEM observations and is partially in accordance with what described by other authors. The ability of Fusarium species, to systemically move along the stem up to the head, following stem-base infection, was already investigated on soft wheat (Mudge et al. 2006, Covarelli et al. 2012, Winter et al. 2013) and durum wheat (Moretti et al. 2014).

In similar researches on soft wheat, Covarelli et al. (2012) found that $F$. culmorum colonized the stem up to segment II but it was not detected in the last internode. This behavior was also confirmed in a recent study by Beccari et al. (2018) where they used the same Fc820 strain on soft wheat. This reveals the opportunity that in barley, in contrast to what occurs in soft wheat, F. culmorum could systemically colonize the head tissues after stem base inoculation. The movement from stem base, along the stem, up to the head could occur by vascular tissue colonization. F. culmorum begins its colonization from the lowest leaf sheaths damaging the epidermal cells, as already described in wheat (Beccari et al. 2011, Covarelli et al. 2012). SEM observations of barley infected plants, showed damaged tissues in the presence of the fungal hyphae, indicating a similar colonization process. Differently, Covarelli et al. (2012) and Winter et al. (2013) reported that F. culmorum, in wheat, was unable to colonize the head most likely due to the presence of a lignin layer in the parenchymal cells of the culm. A similar phenomena was described for F. graminearum in durum wheat where the pathogen was not able to reach the head, probably because of a kind of barrier (Moretti et al. 2014).

Mudge et al. (2006) described how F. graminearum and F. pseudograminearum colonize the stem tissues of soft wheat penetrating the epidermis of the leaf sheath and from the leaf insertion site invaded the parenchymal tissues adjacent to the epidermal layer and then colonized the stem by an intercellular pathway. The present study showed as in barley, differently from what reported by Mudge et al. (2006) in soft wheat, the colonization by $F$. pseudograminearum strain CS3427 was limited to the basal portions (up to segment II), in accordance to what reported by Backhouse et al. (2004) in FCR investigations conducted in Australia.

Concerning DON translocation, this study proved that DON was present in high concentrations in the segments I and II of barley plants inoculated with F. culmorum strain Fc820 and at lower concentrations in the other portions of plant (segments III and IV) head included. These data are related with the quantification of $F$. culmorum strain Fc820 biomass and also with the work of Covarelli et al. (2012) that showed a decreasing concentration of DON from the stem-base to the head of soft wheat. DON translocation from the base to the head was also detected in soft wheat plants inoculated at the stem-base with F. graminearum and F. pseudograminearum (Mudge et al. 2006) and it was observed how this characteristic is depending on strain aggressiveness, such as symptoms extension and fungal colonization (Beccari et al. 2018). In addition, Mudge et al. (2006) demonstrated how strains $F$. graminearum mutant for tri5 gene (responsible for DON biosynthesis) were unable to colonize the adjacent area of the flag leaf in soft wheat. Therefore DON interferes with the protein synthesis mechanism of the plant, blocking its defense mechanisms, thus facilitating the advancement of the fungus from the base of the culm to the head. DON, being water-soluble, is transported remotely through the transpiration flux in xylem vessels, accumulating also in elevated quantities at the head level (Berthiller et al. 2013). The systemic translocation of DON from the stem base to the head was also reported in soft wheat by Covarelli et al. (2012) and Winter et al. (2013). Winter et al. (2013) observed that, in soft wheat plants inoculated with F. culmorum, DON was present at high concentrations at the base of the plant and moved to the apical parts through xylematic flow, where it is converted in its conjugated product DON-3-glucoside (DON-3G), reaching chaff and awns tissues but not the grains. Covarelli et al. (2012) reported in soft wheat a higher DON concentration in the chaff and rachis in comparison to the grains.

To our knowledge, this is the first report about the barley systemic colonization of three mycotoxigenic FCR causal agents (F. culmorum, F. graminearum and F. pseudograminearum) in particular, in this study F. culmorum and $F$. graminearum colonized barley plants systemically, whereas F. pseudograminearum did not. Translocation of DON up the xylem was only shown indirectly and only for F. pseudograminearum which did not colonize the segments III and IV, and yet DON was detected in these segments.

This investigation indicates that FCR infections in barley may represents a supplementary route, as already demonstrated for wheat, for the accumulation of DON in the head tissues, in addition to FHB. 


\section{Acknowledgements}

The Authors wish to thank Dr Gloria Innocenti and Dr Davide Pancaldi for supporting Marta Giannini's PhD project. The Authors wish to thank Prof. and Andrea Onofri, Dept. of Agricultural, Food and Environmental Sciences of the University of Perugia, for contributing to the statistical analysis of data.

\section{References}

Alkadri, D., Nipoti, P., Döll, K., Karlovsky, P., Prodi, A. \& Pisi, A. 2013. Study of fungal colonization of wheat kernels in Syria with a focus on Fusarium species. International Journal of Molecular Science 14: 5938-5951. https://doi.org/10.3390/ijms14035938

Akinsanmi, O.A., Mitter, V., Simpfendorfer, S., Backhouse, D. \& Chakraborty, S. 2004. Identity and pathogenicity of Fusarium spp. isolated from wheat fields in Queensland and northern New SouthWales. Australian Journal of Agriculture Research 55: 97-107. https://doi.org/10.1071/AR03090

Antonissen, G., Martel, A., Pasmans, F., Ducatelle, R., Verbrugghe, E., Vandenbroucke, V., Li, S., Haesebrouck, F., Immerseel, F.V. \& Croubels, S. 2014. The impact of Fusarium mycotoxins on human and animal host susceptibility to infectious diseases. Toxins 6: 430-452. https://doi.org/10.3390/toxins6020430

Backhouse, D., Abubakar, A.A., Burgess, L.W., Dennisc, J.I., Hollaway, G.J., Wildermuth, G.B., Wallwork, H. \& Henry, F.J. 2004. Survey of Fusarium species associated with crown rot of wheat and barley in eastern Australia. Australasian Plant Pathology 33: 255-261. https://doi.org/10.1071/AP04010

Beccari, G., Caproni, L., Tini, F., Uhlig, S. \& Covarelli, L. 2016. Presence of Fusarium species and other toxigenic fungi in malting barley and multi-mycotoxin analysis by liquid chromatography-high-resolution mass spectrometry. Journal of Agriculture and Food Chemistry 64: 4390-4399. https://doi.org/10.1021/acs.jafc.6b00702

Beccari, G., Covarelli, L. \& Nicholson, P. 2011. Infection processes and soft wheat response to root rot and crown rot caused by Fusarium culmorum. Plant Pathology 60: 671-684. https://doi.org/10.1111/j.1365-3059.2011.02425.x

Beccari, G., Prodi, A., Pisi, A., Nipoti, P., Onofri, A., Nicholson, P., Pfohl, K., Karlovsky, P., Gardiner, D.M. \& Covarelli, L. 2018. Development of three fusarium crown rot causal agents and systemic translocation of deoxynivalenol following stem base infection of soft wheat. Plant Pathology, Article in Press. http://onlinelibrary.wiley.com/doi/10.1111/ppa.12821/full. https://doi. org/10.1111/ppa.12821

Beccari, G., Prodi, A., Tini, F., Bonciarelli, U., Onofri, A., Oueslati, S., Limayma, M. \& Covarelli, L. 2017. Changes in the Fusarium head blight complex of malting barley in a tree-year field experiment in Italy. Toxins 9: 1-18. https://doi.org/10.3390/toxins9040120

Berguete, E.M. 2012. Fusarium spp. mycotoxins in the European malting barley chain. RIKILT Wageningen UR: Wageningen, The Netherlands. 45 p. DOI: 10.13140/2.1.3744.2881.

Berthiller, F., Crews, C., Dall'Asta, C., Saeger, S.D., Haesaert, G., Karlovsky, P., Oswald, I.P., Seefelder, W., Speijers, G. \& Stroka, J. 2013. Masked mycotoxins: A review. Molecular Nutrition \& Food Research 57: 165-186. https://doi.org/10.1002/mnfr.201100764

Bertuzzi, T., Rastelli, S., Mulazzi, A., Donadini, G. \& Pietri, A. 2011. Mycotoxin occurrence in beer produced in several European countries. Food Control 22: 2059-2064. https://doi.org/10.1016/j.foodcont.2011.06.002

Bottalico, A. \& Perrone, G. 2002. Toxigenic Fusarium species and mycotoxins associated with head blight in small-grain cereals in Europe. European Journal of Plant Pathology 108: 611-624. https://doi.org/10.1023/A:1020635214971

Bretz, F., Hotorn, T. \& Westfall, P. 2011. Multiple comparisons using R. Boca Raton, FL, USA: CRC Press.

Burgess, L.W., Backhouse, D., Summerell, B.A. \& Swan, L.J. 2001. Crown rot of wheat. In: Summerell, B., Leslie, J., Backhouse, D., Bryden, W. \& Burgess L. (eds.). Fusarium: Paul E. Nelson Memorial Symposium. St. Paul, MN, USA: American Phytopathological Society Press. p. 271-294.

Covarelli, L., Beccari, G., Steed, A. \& Nicholson, P. 2012. Colonization of soft wheat following infection of the stem base by Fusarium culmorum and translocation of deoxynivalenol to the head. Plant Pathology 61: 1121-1129. https://doi.org/10.1111/j.13653059.2012.02600.x

Covarrubias, J.I., Pisi, A. \& Rombolà, A.D. 2014. Evaluation of sustainable management techniques for preventing iron chlorosis in the grapevine. Australian Journal of Grape and Wine Research 10: 149-159. https://doi.org/10.1111/ajgw.12055

Christian, M., Titze, J., Ilberg, V. \& Jacob, F. 2011. Novel Perspectives in Gushing Analysis: A Review. Journal of the Institute of Brewing 117: 295-313. https://doi.org/10.1002/j.2050-0416.2011.tb00474.x

de Nijs, M., Larsen, J., Gams, W., Rombouts, F.M., Wernars, K., Thrane, U. \& Notermans, S.H.W. 1997. Variations in random polymorphic DNA patterns and secondary metabolite profiles within Fusarium species from cereals from various parts of the Netherlands. Food Microbiology 14: 449-459. https://doi.org/10.1006/fmic.1997.0111

Dyer, A.T., Johnston, R.H., Hogg, A.C. \& Johnston, J.A. 2009. Comparison of pathogenicity of the Fusarium crown rot (FCR) complex (F. culmorum, F. pseudograminearum and F. graminearum) on hard red spring and durum wheat. European Journal of Plant Pathology 125: 387-395. https://doi.org/10.1007/s10658-009-9488-1

Engle, J.S., Lipps, P.E., Graham, T.L. \& Boehm, M.J. 2004. Effects of choline, betaine, and wheat floral extracts on growth of Fusarium graminearum. Plant Disease 88: 175-180. https://doi.org/10.1094/PDIS.2004.88.2.175

Faraway, J.J. 2006. Extending the linear model with R. Generalized linear, mixed effects and nonparametric regression model. Text in statistical sciences. Boca Raton, FL, USA: Chapman \& Hall.

Garbe, L.A., Schwarz, P.I. \& Ehmer, A. 2008. Beer gushing. Handbook of Alcoholic Beverages Series, Beer A Quality perspective p. $185-212$ 
Hogg, A.C., Johnston, R.H., Johnston, J.A., Klouser, L., Kephart, K.D. \& Dyer, A.T. 2010. Monitoring Fusarium crown rot populations in spring wheat residues using quantitative real-time polymerase chain reaction. Phytopathology 100: 49-57. https://doi. org/10.1094/PHYTO-100-1-0049

Hollaway, G.J., Evans, M.L., Wallwork, H., Dyson, C.B. \& McKay, A.C. 2013. Yield loss in cereals, caused by Fusarium culmorum and F. pseudograminearum, is related to fungal DNA in soil prior to planting, rainfall, and cereal type. Plant Disease 97: 977-982. https://doi.org/10.1094/PDIS-09-12-0867-RE

Hückelhoven, R., Hofer, K., Coleman, A. \& Heß, M. 2018. Fusarium infection of malting barley has to be managed over the entire value chain. Journal of Plant Disease and Protection 125: 1-4. https://doi.org/10.1007/s41348-017-0101-0

Jennings, P., Coates, M.E., Turner, J.A., Chandler, E.A. \& Nicholson, P. 2004. Determination of deoxynivalenol and nivalenol chemotypes of Fusarium culmorum isolates from England and Wales by PCR assay. Plant Pathology 53: 182-190. https://doi.org/10.1111/ j.0032-0862.2004.00985.x

Knight, N.L. \& Sutherland, M.W. 2016. Histopathological assessment of Fusarium pseudograminearum colonization of cereal culms during crown rot infections. Plant Disease 100: 252-259. https://doi.org/10.1094/PDIS-04-15-0476-RE

Khudhair, M., Melloy, P., Lorenz, D.J., Obanor, F., Aitken, E., Datta, S., Fitzgerald, G. \& Chakraborty, S. 2014. Fusarium crown rot under continuous cropping of susceptible and partially resistant wheat in microcosms at elevated CO2. Plant Pathology 63: 10331043. https://doi.org/10.1111/ppa.12182

Lamprecht, S.C., Marasas, W.F.O., Hardy, M.B. \& Calitz, F.J. 2006. Effect of crop rotation on crown rot and the incidence of Fusarium pseudograminearum in wheat in the Western Cape, South Africa. Australasian Plant Pathology 35: 419-426. https://doi. org/10.1071/AP06040

Moretti, A., Panzarini, G., Somma, S., Campagna, C., Ravaglia, S., Logrieco, A. \& Solfrizzo, M. 2014. Systemic growth of F. graminearum in wheat plants and related accumulation of deoxynivalenol. Toxins 6: 1308-1324. https://doi.org/10.3390/toxins6041308

Mudge, A.M., Dill-Macky, R., Dong, Y., Gardiner, D.M., White, R.G. \& Manner, J.M. 2006. A role for the mycotoxin deoxynivalenol in stem colonisation during crown rot disease of wheat caused by Fusarium graminearum and Fusarium pseudograminearum. Physiological and Molecular Plant Pathology 69: 73-85. https://doi.org/10.1016/j.pmpp.2007.01.003

Muthomi, J.W., Schütze, A., Dehne, H.W., Mutitu, E.W. \& Oerke, E.C. 2000. Characterization of Fusarium culmorum isolates by mycotoxin production and aggressiveness to winter wheat. Journal of Plant Disease 107: 113-123.

Nicholson, P., Simpson, D.R., Weston, G., Rezanoor, H.N., Lees, A.K., Parry, D.W. \& Joyce, D. 1998. Detection and quantification of Fusarium culmorum and Fusarium graminearumin cereals using PCR assays. Physiological and Molecular Plant Pathology 53: 17-37. https://doi.org/10.1006/pmpp.1998.0170

Nielsen, L.K., Cook, D.J., Edwards, S.G. \& Ray R.V. 2014. The prevalence and impact of Fusarium head blight pathogens and mycotoxins on malting barley quality in UK. International Journal of Food Microbiology 179: 38-49. https://doi.org/10.1016/j.ijfoodmicro.2014.03.023

Oliveira, P.M., Waters, D.M. \& Arendt, E.K. 2013. The impact of Fusarium culmorum infection on the protein fractions of raw barley and malted grains. Applied Microbiology 97: 2053-2065. https://doi.org/10.1007/s00253-013-4696-1

Pancaldi, D., Tonti, S., Prodi, A., Salomoni, D., Dal Prà, M., Nipoti, P., Alberti, I. \& Pisi, A. 2010. Survey of the main causal agents of fusarium head blight of durum wheat around Bologna, northern Italy. Phytopathologia mediterranea 49: 58-66.

Parry, D.W., Jenkinson, P. \& McLeod, L. 1995. Fusarium ear blight (scab) in small grain cereals-a review. Plant Pathology 44: 207238. https://doi.org/10.1111/j.1365-3059.1995.tb02773.x

Purahong, W., Alkadri, D., Nipoti, P., Pisi, A, Lemmens, M, Prodi, A. 2012. Validation of a modified Petri-dish test to quantify aggressiveness of Fusarium graminearum in durum wheat. European Journal of Plant Pathology 132: 381-391. https://doi.org/10.1007/ s10658-011-9883-2

R Core Team 2017. R: A language and environment for statistical computing. R foundation for statistical computing, Vienna, Austria. URL http://www.R-project.org/.

Sarlin, T., Nakari Setälä, T., Linder, M., Penttilä, M. \& Haikara, A. 2005. Fungal hydrophobins as predictors of the gushing activity of malt. Journal of the Institute of Brewing 111: 105-111. https://doi.org/10.1002/j.2050-0416.2005.tb00655.x

Scherm, B., Balmas, V., Spanu, F., Pani, G., Delogu, G., Pasquali, M. \& Migheli Q. 2013. Fusarium culmorum: causal agent of foot and root rot and head blight on wheat. Molecular Plant Pathology 14: 323-341. https://doi.org/10.1111/mpp.12011

Schwarz, P.B. 2017. Fusarium head blight and deoxynivalenol in malting and brewing: successes and future challenges. Tropical Plant Pathology 42: 153-164. https://doi.org/10.1007/s40858-017-0146-4

Simpson, D.R., Rezanoor H.N., Parry, D.W. \& Nicholson, P. 2000. Evidence for differential host preference in Microdochium nivale var. majus and Microdochium nivale var. nivale. Plant Pathology 49: 261-268. https://doi.org/10.1046/j.1365-3059.2000.00453.x

Smiley, R.W., Gourlie, J.A., Easley, S.A., Patterson, L.M. \& Whittaker, R.G. 2005. Crop damage estimates for crown rot of wheat and barley in the Pacific Northwest. Plant Disease 89: 595-604. https://doi.org/10.1094/PD-89-0595

Southwell, R.J., Moore, K.J., Manning, W. \& Hayman, P.T. 2003. An outbreak of fusarium head blight of durum wheat on the Liverpool plains in northern New South Wales in 1999. Australasian Plant Pathology 32: 465-71. https://doi.org/10.1071/AP03061

Stephens, A.E., Gardiner, D.M., White, R.G., Munn, A.L. \& Manners, J.M. 2008. Phases of infection and gene expression of Fusarium graminearum during crown rot disease of wheat. Molecular Plant-Microbe Interactions 21: 1571-1581. https://doi.org/10.1094/ MPMI-21-12-1571

Waalwijk, C., Kastelein, P., de Vries, I., Kerényi, Z., van der Lee, T., Hesselink, T., Köhl, J. \& Kema, G. 2003. Major changes in Fusarium spp. in wheat in the Netherlands. European Journal of Plant Pathology 109: 743-754. https://doi.org/10.1023/A:1026086510156

West, J.S., Holdgate, S., Townsend, J.A., Edwards, S.G., Jennings, P. \& Fitt, B.D.L. 2012. Impacts of changing climate and agronomic factors on fusarium ear blight of wheat in the UK. Fungal Ecology 5: 53-61. https://doi.org/10.1016/j.funeco.2011.03.003 
Winter, M., Koopmann, B., Döll, K., Karlovsky, P., Kropf, U., Schlüter, K. \& von Tiedemann, A. 2013. Mechanisms regulating grain contamination with trichothecenes translocated from the stem base of wheat (Triticum aestivum) infected with Fusarium culmorum. Phytopathology 103: 682-689. https://doi.org/10.1094/PHYTO-11-12-0296-R

Wolf-Hall, C.E. 2007. Mold and mycotoxin problems encountered during malting and brewing. International Journal of Food Microbiology 119: 89-94. https://doi.org/10.1016/j.ijfoodmicro.2007.07.030

Xu, X.M., Parry, D.W., Nicholson, P., Thomsett, M.A., Simpson, D., Edwards, S.G., Cooke, B.M., Doohan, F.M., Brennan, J.M., Moretti, A., Tocco, G., Mulè, G., Hornok, L., Giczey, G. \& Tatnell, J. 2005. Predominance and association of pathogenic fungi causing Fusarium ear blight in wheat in four European countries. European Journal of Plant Pathology 112: 143-154. https://doi. org/10.1007/s10658-005-2446-7

Xu, X. \& Nicholson, P. 2009. Community ecology of fungal pathogens causing wheat head blight. Annual Review of Phytopathology 47: 83-103. https://doi.org/10.1146/annurev-phyto-080508-081737

The Brewers of Europe 2015. http://www.brewersofeurope.org/uploads/mycms-files/documents/ publications/2015/statistics_2015_v3.pdf. Accessed 15 December 2016 